\title{
The efficacy of psychosocial factors in predicting pain and functional outcomes following knee replacement surgery
}

\section{Philip Jefferies, Laura Coffey, Pamela Gallagher}

10.1136/ebnurs-2012-100563

School of Nursing and Human Sciences, Dublin City University, Dublin, Ireland

\section{Correspondence to:}

Pamela Gallagher

School of Nursing and Human Sciences, Dublin City University, Collins Avenue, Dublin 9, Ireland; Pamela.Gallagher@dcu.ie

\author{
Commentary on: Lopez-Olivo MA, Landon GC, Siff SJ, et al. Psychosocial determinants of outcomes in \\ knee replacement. Ann Rheum Dis 2011;70:1775-81.
}

\section{Implications for practice and research}

- Psychosocial variables can help to explain patient outcomes following total knee replacement.

- In particular, lower levels of depressive symptomatology and dysfunctional coping, and higher levels of education, problem-focused coping, internal health locus of control and perceived adequacy of assistance from others were predictive of enhanced outcomes at 6 months postsurgery.

- Rehabilitation providers should consider the merit of incorporating and evaluating psychosocial screening tools to identify individuals at risk of poor outcomes.

- Research is needed on the effectiveness of interventions targeting these psychosocial variables.

- Rehabilitation providers should consider the merit of incorporating interventions such as coping skills training into existing programmes to improve postsurgery outcomes.

\section{Context}

Approximately a quarter of individuals who undergo knee replacement exhibit little or no improvement after surgery, or are unsatisfied with their outcome, ${ }^{1}$ despite having no apparent clinical or technical issues. Psychosocial factors may act as barriers to successful rehabilitation in this patient group.

\section{Methods}

Lopez-Olivo et al explored the psychosocial variables affecting rehabilitation in individuals undergoing total knee replacement surgery. A prospective cohort study of 241 patients aged 56-74 years $(M=65 \pm 9)$ was conducted, in which demographic, educational, psychosocial and outcome variables were examined 1 month or less before surgery and 6 months after surgery. Outcomes were assessed by examining pain and function via a self-assessed questionnaire (pain and function subscales of the Western Ontario McMaster scale, WOMAC) and by trained personnel using the knee and function subscales of the knee society rating system (KSRS). Six self-reported psychosocial questionnaires examined social support (Medical Outcome StudySocial Support Scale) depression, anxiety and stress (Depression, Anxiety and Stress Scale), coping responses to stressors (COPE Inventory Brief Version), health locus of control (Multidimensional Health Locus of Control
Scales), self-efficacy (Arthritis Self-Efficacy Scale) and optimism (Life Orientation Test-Revised). Stepwise linear regression analyses were applied to data, controlling for body mass index (BMI), comorbidities and baseline outcome scores.

\section{Findings}

The findings of the study demonstrated an overall improvement in outcomes at 6 months postsurgery. Analyses determined that lower education, less tangible social support, depression, less problem-solving coping, more dysfunctional coping, and poorer internal locus of control were associated with worse WOMAC scores, and older age, lower education, depression and less problemsolving coping were associated with poorer KSRS scores. Problem-solving coping was an independent predictor of all outcome measures, and depression was an independent predictor of WOMAC function, KSRS function and KSRS total scores. Psychosocial attributes accounted for approximately $7-14 \%$ of the variance in outcomes. The authors note that some of the psychosocial variables may be interrelated, as variables such as anxiety and stress, while significantly impacting outcomes when clustered, were not predictive individually.

\section{Commentary}

In a field in which research is predominantly focused on clinical factors, it is encouraging to find a study that has explored the influence of psychosocial variables on patient outcomes. Strengths of the study include its longitudinal design, the fact that baseline outcome scores, BMI and comorbidities were controlled for in the regression analyses, and the use of standardised measures, which enables easier comparison to other studies. However, the authors themselves recognise the limitation for generalisation that their self-selecting participant group may present. The knee society rating system also raises problems due to its low internal consistency.

Additionally, care should be taken when defining what constitutes a successful outcome. Function and pain are two useful dimensions, but it is also important to identify whether patients' own values and expectations have been met. Future studies may find utility in incorporating more holistic outcome measures that also take into account the perceptions and preferences of the individual, such as assessments of quality of life or participation (please refer to the WHO International Classification of 
Functioning and Health), ${ }^{2}$ which could provide a more robust evaluation of surgical success.

Practitioners may consider the merit of incorporating psychosocial screening tools to identify vulnerable patients, but further research is first needed to better understand what constitutes a successful outcome, and what psychosocial variables might contribute towards this. The effectiveness of interventions targeting psychosocial variables also requires examination in this patient group. Rehabilitation providers should consider the merit of incorporating interventions such as coping skills training into existing programmes to improve postsurgery outcomes. In summary, this study represents a useful starting point for understanding psychosocial predictors of outcomes following total knee replacement.

Competing interests None.

\section{References}

1. Jones CA, Voaklander DC, Johnston DW, et al. Health related quality of life outcomes after total hip and knee arthroplasties in a community based population. J Rheumatol 2000;27:1745-52.

2. World Health Organization. ICF: International Classification of Functioning, Disability and Health. Geneva: World Health Organization, 2001. 


\section{ERN The efficacy of psychosocial factors in predicting pain and functional outcomes following knee replacement surgery}

Philip Jefferies, Laura Coffey and Pamela Gallagher

Evid Based Nurs 2012 15: 92-93 originally published online March 22, 2012

doi: 10.1136/ebnurs-2012-100563

Updated information and services can be found at:

http://ebn.bmj.com/content/15/3/92

These include:

References This article cites 2 articles, 1 of which you can access for free at: http://ebn.bmj.com/content/15/3/92\#BIBL

Email alerting

Receive free email alerts when new articles cite this article. Sign up in the service box at the top right corner of the online article.

Topic

Articles on similar topics can be found in the following collections

Collections

Pain (neurology) (309)

Screening (public health) (190)

Mood disorders (including depression) (84)

\section{Notes}

To request permissions go to:

http://group.bmj.com/group/rights-licensing/permissions

To order reprints go to:

http://journals.bmj.com/cgi/reprintform

To subscribe to BMJ go to:

http://group.bmj.com/subscribe/ 